Revue

Revue de l'histoire des religions

de Ihistoire des religions

Paolo BROGGIO, La teologia e la politica. Controversie dottrinali, Curia romana e Monarchia spagnola tra Cinque e Seicento

Florence, Leo S. Olschki, 2009, XXVIII-224 p.

Sylvio Hermann De Franceschi

\title{
CpenEdition
}

Journals

Édition électronique

URL : http://journals.openedition.org/rhr/7808

DOI : $10.4000 /$ rhr.7808

ISSN : 2105-2573

Éditeur

Armand Colin

Édition imprimée

Date de publication : 1 septembre 2011

Pagination : 458-459

ISBN : 978-2200-92721-9

ISSN : 0035-1423

Référence électronique

Sylvio Hermann De Franceschi, « Paolo BROGGIO, La teologia e la politica. Controversie dottrinali, Curia romana e Monarchia spagnola tra Cinque e Seicento ", Revue de l'histoire des religions [En ligne], 3 | 2011, mis en ligne le 09 décembre 2011, consulté le 22 septembre 2020. URL : http:// journals.openedition.org/rhr/7808; DOI : https://doi.org/10.4000/rhr.7808

Ce document a été généré automatiquement le 22 septembre 2020

Tous droits réservés 


\section{Paolo BROGGIO, La teologia e la politica. Controversie dottrinali, Curia romana e Monarchia spagnola tra Cinque e Seicento}

Florence, Leo S. Olschki, 2009, XXVIII-224 p.

Sylvio Hermann De Franceschi

\section{RÉFÉRENCE}

Paolo Broggio, La teologia e la politica. Controversie dottrinali, Curia romana e Monarchia spagnola tra Cinque e Seicento, Florence, Leo S. Olschki, 2009, XXVIII-224 p., $24 \mathrm{~cm}$ («Biblioteca della Rivista di storia e letteratura religiosa. Studi », 22), $27 €$

1 La dignité d'objet d'histoire a longtemps été refusée à la théologie de l'époque moderne par une corporation historienne méfiante à l'égard de l'histoire des idées en général, et des théologiques en particulier. Depuis trois décennies, toutefois, un regain d'intérêt semble se dessiner, soutenu en France par la publication des travaux de Bruno Neveu et de Jean-Louis Quantin et en Italie par les études de Pietro Stella. Le récent livre de Paolo Broggio tire le meilleur profit des résultats déjà accumulés pour promouvoir une nouvelle lecture des querelles doctrinales dans l'espace catholique européen des temps posttridentins.

Développant une approche qu'il avait déjà amorcée dans une précédente publication (« Ordini religiosi tra cattedra e dispute teologiche : note per una lettura socio-politica della controversia de auxiliis (1582-1614)», Religione, conflittualità e cultura. Il clero regolare nell'Europa d'antico regime, éd. M. C. GIANNINI, Cheiron. Materiali e strumenti di aggiornamento storiografico, XXII/43-44, 2005, p.53-86), Paolo Broggio annonce d'emblée son propos : il ne s'agit pas pour lui de s'en tenir à la seule perspective des historiens classiques de la théologie, qui souhaitaient surtout mettre en lumière le 
contenu des disputes, mais de montrer également les modalités de la "politisation ", politicizzazione, des querelles religieuses, en d'autres termes comment les controverses théologiques deviennent objets de différends politiques et diplomatiques et comment elles en viennent parfois à « descendre dans la rue » et à se populariser.

3 Paolo Broggio a choisi de concentrer son attention sur deux grandes disputes du tournant des $\mathrm{XVI}^{\mathrm{e}}$ et $\mathrm{XVII}{ }^{\mathrm{e}}$ siècles, celle de la grâce et celle de l'Immaculée Conception, qui voient l'affrontement des dominicains et des jésuites, deux ordres largement inféodés à la puissance espagnole. Il souligne le fait que si la théologie est devenue l'un des terrains sur lesquels s'est jouée l'évolution des rapports entre le Saint-Siège et les puissances séculières, alors force est de supposer que les théologiens eux-mêmes, en tant que «professionnels » de la théologie, n'ont pas pu ne pas en subir le contrecoup.Se pose en particulier la question de la formation d'une théologie proprement romaine dont l'expression pouvait éventuellement être destinée à peser sur le cours de querelles dont se mêlaient les couronnes française et espagnole.

4 Un premier chapitre brosse un panorama stimulant des conditions de production de la théologie à Rome dans la deuxième moitié du Xvi ${ }^{\mathrm{e}}$ siècle. Paolo Broggio relève à juste titre l'écrasante et naturelle prépondérance des théologiens espagnols chez les dominicains et les jésuites, ainsi que la concurrence que se livrent les deux familles pour savoir laquelle des deux est la plus fidèle aux enseignements de saint Thomas. Le rôle du pontificat de Grégoire XIII est essentiel: le pape a voulu établir une uniformisation de l'enseignement théologique dans l'Église et, pour faire triompher son dessein, a favorisé de sa bienveillance la Compagnie de Jésus. Entreprise poursuivie sous le pontificat de Clément VIII, lorsque les jésuites adoptent finalement, en 1599, le texte définitif de leur Ratio Studiorum.

5 Dans un contexte de rivalité accrue éclate la controverse de auxiliis. On sait qu'elle a eu pour origine la publication en 1588 de la Concordia liberi arbitrii cum gratice donis du jésuite Luis de Molina, qui exposait pour la première fois sa célèbre théorie de la science moyenne, fondatrice précisément du molinisme. Effarés par une doctrine qui leur semblait contrevenir frontalement aux enseignements de l'Aquinate, les dominicains ont aussitôt répliqué. L'affrontement paraissait inextinguible lorsque Clément VIII évoque l'affaire en cour de Rome et fait organiser les fameuses Congrégations de auxiliis. Dans ses chapitres II, III et IV, Paolo Broggio revient de manière détaillée sur le déroulement de la dispute et sur le rôle qu'y ont tenu les souverains français et espagnol. Avec une minutie qui force l'admiration et une documentation inédite extrêmement riche - et de surcroît difficile à trouver -, Paolo Broggio parvient à retracer l'exacte évolution des positions manifestées par le pouvoir hispanique et souligne la portée politique du geste fait par Clément VIII lorsqu'il décide de réserver à Rome la solution du différend alors que l'Inquisition espagnole s'apprêtait à statuer. Dans le sillage des récents travaux d'Adriano Prosperi ("L'Immacolata a Siviglia e la fondazione sacra della monarchia spagnola ", Studi Storici, XLVII/2, 2006, p. 481-510), un dernier chapitre, consacré à la querelle de l'Immaculée Conception sous les règnes de Philippe III et de Philippe IV, montre qu'à plusieurs égards, en adoptant les thèses immaculistes, la couronne espagnole a voulu peser sur le Saint-Siège et remporter, par une sorte de phénomène compensatoire, une victoire qui la dédommageât du camouflet essuyé en 1598 lorsque Clément VIII avait ouvert les Congrégations de auxiliis. Point de vue politique auquel la controverse sur l'Immaculée 
Conception ne fait que poursuivre la lutte d'influence ouverte par la querelle de la grâce.

Il est difficile de rendre pleinement compte de la richesse de l'ouvrage de Paolo Broggio, qui intervient dans un champ d'études où il reste beaucoup à faire. On retient de sa lecture l'idée, essentielle, d'une contamination entre conscience nationale et thèses théologiques, interprétation que les historiens espagnols du XIX siècle, ainsi qu'il est judicieusement rappelé, ont largement contribué à vulgariser: naturellement immaculiste, l'Espagne ne pouvait que bénéficier du patronage préférentiel de la Vierge. Généralement tenue pour un domaine de spéculation pure, la théologie apparaît finalement, bien plus qu'on ne le pensait, comme un champ intensément politisé. À Paolo Broggio, le mérite de l'avoir illustré avec rigueur et saine méthode d'historien.

\section{AUTEUR}

\section{SYLVIO HERMANN DE FRANCESCHI}

École pratique des Hautes Études (IV ${ }^{\mathrm{e}}$ section), Paris 